\title{
ANALISIS NARASI VISUAL POSTER ASIAN GAMES 2018 VERSI PANAHAN (Mel Ahyar)
}

\author{
Fadhly Abdillah, Purmaningrum Maeni, Erna Nurmalinda \\ Program Studi Desain Komunikasi Visual, Universitas Pasundan Bandung
}

\begin{abstract}
Abstrak. Poster merupakan salah satu media konvensional yang sering digunakan untuk menyampaikan sebuah pesan, terutama dalam konsep periklanan, baik itu iklan produk, jasa maupun sebuah kegiatan. Asian games merupakan ajang olahraga wilayah Asia empat tahunan yang diselenggarakan di salah satu negara di Asia, yang pada aktivitasnya promosinya membutuhkan media, salah satunya adalah poster dalam menyampaikan informasi kegiatannya, baik itu sebelum berlangsung, ketika berlangsung, dan juga setelah kegiatan berlangsung. Tulisan ini membahas bagaimana analisis narasi visual dari poster Asian Games 2018 versi panahan. Dengan menggunakan pendekatan tinjauan desain, dan analisis narasi visual. Tinjauan desain dipakai sebagai metoda dalam memecah tahapan tahapan analisis, antara lain, deskripsi obyektif, analisis formal, interpretasi dan penilaian. Sedangkan narasi visual, yang merupakan cabang dari teori budaya visual digunakan sebagai pisau penelitian untuk menganalisis expectation, attention dan memory. Hasil analisis ini adalah pesan yang ingin disampaikan pada poster ini bahwa kita bangsa Asia pada umumya dan warga Indonesia pada khususnya merasa bangga dengan kekayaan budaya yang dimiliki, baik itu dalam hal fesyen, sejarah bahkan olahraga, dan harus terus melestarikan juga menjunjung tinggi.
\end{abstract}

Kata Kunci: budaya visual, narasi visual, poster, periklanan, tinjauan desain

\begin{abstract}
Poster is one of the conventional media that is often used to convey a message, especially in the concept of advertising, be it the advertisement of a product, service or an activity. Asian games is a four-yearly Asian sports event held in one of the countries in Asia, whose promotional activities require media, one of which is a poster in conveying information about its activities, both before it takes place, when it takes place, and also after the activity takes place. This paper discusses how the visual narrative analysis of the archery version of the 2018 Asian Games poster. Using a design review approach, and visual narrative analysis. The design review is used as a method of breaking down the stages of analysis, such as objective description, formal analysis, interpretation and assessment. While the visual narrative, which is a branch of visual culture theory, is used as a research knife to analyze expectation, attention and memory. The results of this analysis are the message to be conveyed on this poster, that we Asian people in general and Indonesians in particular feel proud of the cultural wealth they have, both in terms of fashion, history and even sports, and must continue to preserve and uphold.
\end{abstract}

Keywords: visual culture, visual narrative, poster, advertising, design review

Correspondence author: Fadhly Abdillah, fadhlya77@gmail.com, Bandung, Indonesia

This work is licensed under a CC-BY-NC 


\section{PENDAHULUAN}

Secara umum, periklanan dihargai karena dikenal sebagai pelaksana beragam fungsi komunikasi yang penting bagi perusahaan bisnis dan organisai lainnya (Shimp 356) termasuk individu di dalamnya. Aktivitas periklanan sangatlah penting dilakukan, terutama dalam menyampaiakan suatu pesan komunikasi, guna mencapai tujuan yang diinginkan. karena di dalamnya terdapat banyak kemungkinan media yang bisa digunakan, salah satunya adalah poster. Poster merupakan salah satu media konvensional yang masih sering digunakan dalam menyampaikan pesan sebuah produk, baik barang ataupun jasa, dalam sebuah aktivitas periklanan.

Aktivitas periklanan mempunyai fungsi tersendiri, antara lain, informing, persuading, reminding, adding value dan assisting, fungsi-fungsi tersebut harus terlaksana dengan baik (tepat guna) apabila pengiklan menginginkan pesannya sampai dengan efektif. Di samping fungsi, periklanan yang baik harus mempunyai tujuan yang jelas, guna mencapai tujuan tersebut pengiklan wajib memahami apa, mengapa, dimana, siapa, kapan dan bagaimana, sebab tujuan periklanan merupakan ekspresi dan konsensus manajemen (Shimp 366). Pencapaian tujuan periklanan sudah barang tentu berhubungan dengan kendaraan pesan yang digunakan, adalah media sudah barang tentu digunakan sebagai kendaraan yang dipakai untuk menyampaikan pesan kepada khalayak sasarannya.

Pemilihan media yang tepat juga menjadi ukuran keberhasilan suatu aktivitas periklanan, dimana pengiklan wajib memahami efektivitas media yang bisa digunakan dan tepat sasaran. Media periklanan menurut Shimp (504) merupakan metode komunikasi umum yang membawa pesan periklanan. Dengan begitu banyaknya pilihan media, baik itu media konvensional, maupun modern, belum tentu akan tepat digunakan dalam aktivitas ini, mengenal lebih jauh karakter media dan karakter target bisa menjadi kekuatan yang dasyat dalam memilih media.

Media yang hebat dalam menyampaikan pesan adalah media yang mempunyai karakteristik, karakteristiknya mampu menyatu dan hidup dengan targetnya, baik itu menggunakan media cetak maupun media elektronik. Terlepas dari jenisnya, keefektifan penyampain pesan sangat jelas berhubungan dengan karakter media juga, yang mana karakter media sangat jelas mampu menyatu secara langsung dengan targetnya. Para pengiklan berusaha untuk memilih media yang karakteristiknya paling cocok dengan produk yang diiklankan untuk mencapai khalayak sasarannya dalam menyampaikan pesan yang dimaksud.

\section{METODE}

Metode yang digunakan dalam mengkaji poster ini adalah tinjauan desain dengan pendekatan narasi visual. Narasi visual merupakan salah satu cabang ilmu budaya visual, kajian ini merupakan suatu upaya dalam konsep penataan masa lalu, masa kini dan masa yang akan datang, yang didalamnya menggunakan metoda analisis expectation, attention dan memory. Sehingga peneliti mampu menyimpulkan narasi secara diakronik dari media yang dikaji (Piliang), dalam hal ini adalah poster Asian Games 2018.

Poster-poster Asean Games 2018 dengan banyak versi menarik untuk dikaji, bagaimana mereka/pengiklan/panitia menyusun narasi visual dalam menyampaikan pesan kepada khalayak sasarannya (penonton, maupun pelaku olah raga itu sendiri), begitu jelas terlihat expectation, attention dan memory, sehingga pemirsa/sasaran dapat dengan mudah memahami pesan yang ingin disampaikan. Tulisan ini mengkaji/membedah konsep kreatif visual maupun konsep verbal 
dalam poster yang dipakai Asian Games 2018 (versi panahan Mel Ahyar) untuk penyampaikan pesan dalam aktivitas periklanannya.

\section{HASIL DAN PEMBAHASAN}

\section{Landasan Teori}

Narasi Visual

Narasi visual adalah penataan masa lalu, masa kini dan masa yang akan datang melalui analisis Expectation, Attention dan Memori, yang hasilnya adalah bahwa masa depan yang diekspektasinya, melalui masa kini, yang terhadapnya ia hadir ke masa lalu yang diingatnya. Dan untuk memahaminya diperlukan pemahaman terhadap aturan-aturan komposisi dan sintagmatik yang mengatur tatanan diakronik sebuah ceritera (Piliang).

\section{Tinjauan Desain}

Bentuk ikhtiar ilmiah untuk menganalisis, menafsirkan, dan menilai karya desain, khususnya desain komunikasi visual, menngunakan Langkah-langkah tinjauan desain: deskripsi objektif, analisis formal, interpretasi, penilaian/Judgmet.

\section{Deskripsi Obyektif}

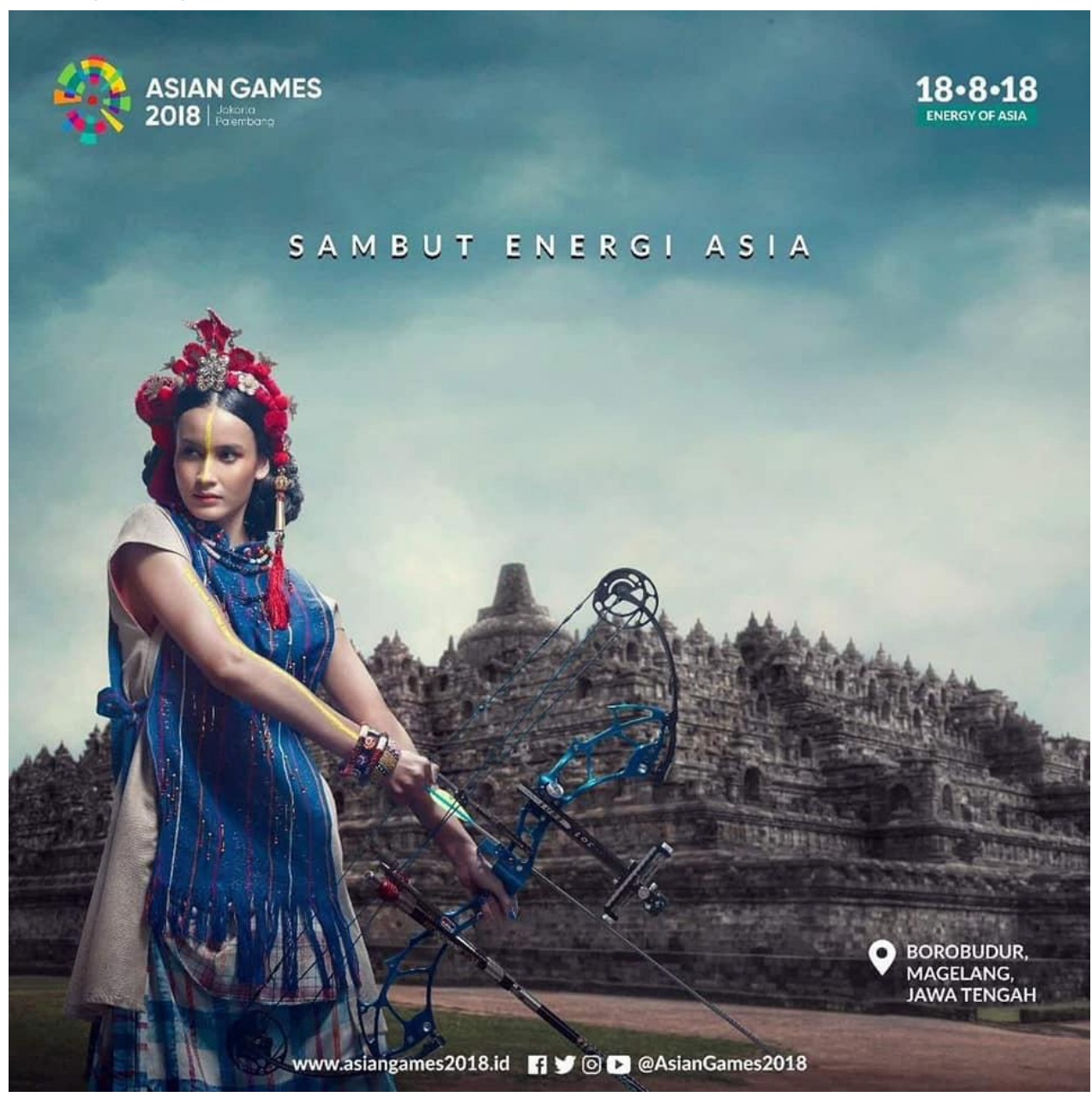

Gambar 1 Poster Asian Games (dok. Daring BrilioNet, 2019) 


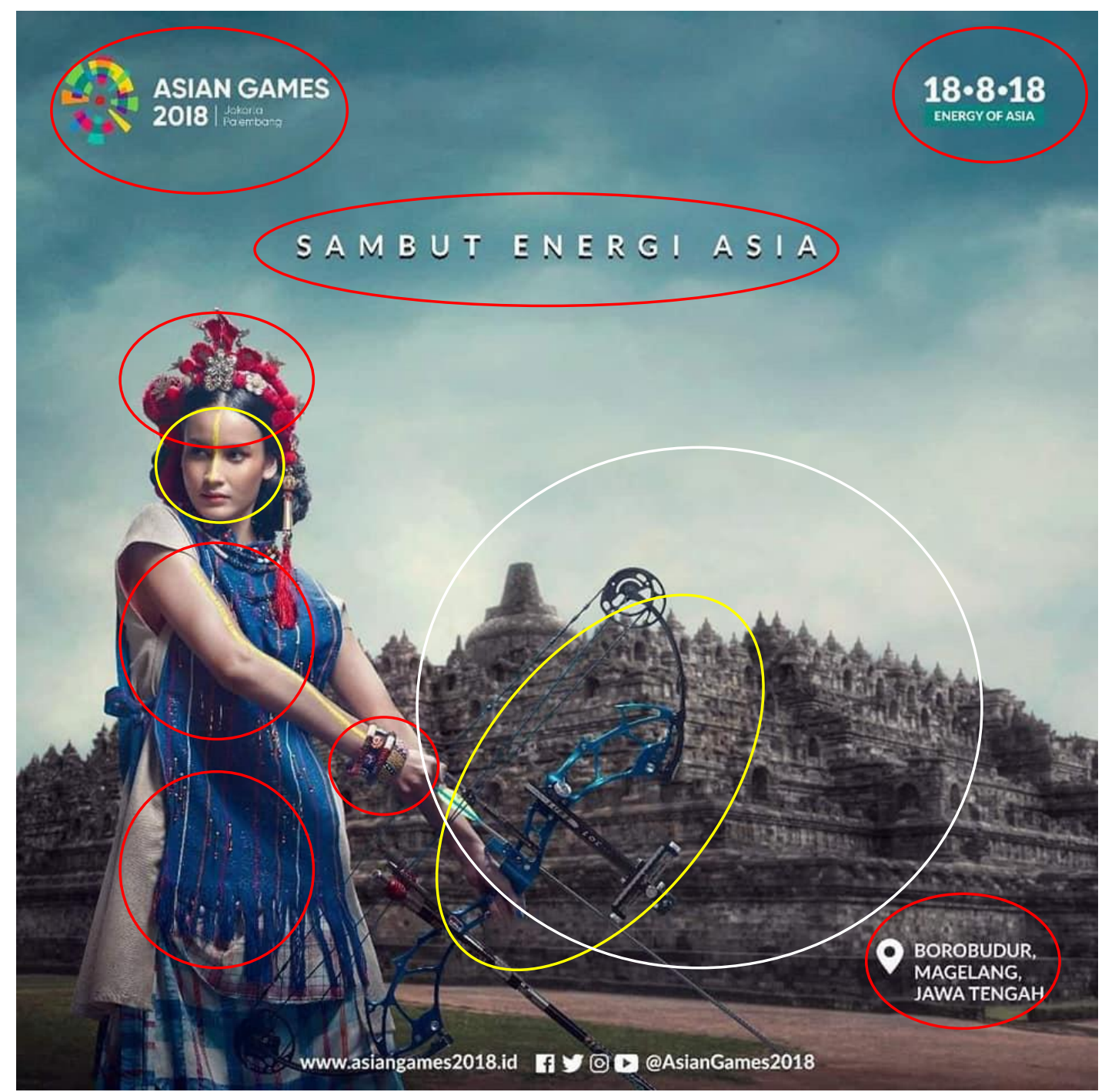

Gambar 2 Poster Asian Games (dok. Daring BrilioNet, 2019)

Dalam tahapan awal ini, analisis yang dilakukan adalah mengamati, menguraikan unsurunsur dalam sebuah karya desain, mentranslasi gambar ke dalam bentuk tulisan, antara lain: Olah raga panahan, logo, alamat, mahkota, pakaian dalam bentuk kain tenun, wajah model iklan terlihat garis-garis kuning yang membelah wajah, Candi Borobudur, alamat sosial, juga tanggal.

Poster ini memperlihatkan pada bagian kiri poster terlihat seorang model (Mel Ahyar), berdiri menggunakan pakaian berupa kain tenun dan sarung berwarna biru, krem, berpadu kontras dengan headpice merah menutupi bagian mahkota sang model yang dibelah tengah, sambil membawa peralatan olahraga panahan (busur) berwarna biru dengan list hitam yang terlihat tidak utuh, sambil sedikit dibentangkan tali busurnya, pada bagian tengah wajah model iklan terlihat garis kuning membelah wajah dari bagian atas kening menuju antara kedua mata dan berakhir di ujung hidung, kedua matanya menatap tajam ke arah bagian kanan dirinya, sementara di lengan kanannya memakai aksessoris empat buah gelang gelang khas dari nusantara. Sang model iklan seolah olah berdiri di atas lapangan rumput, dengan latar tepat bagian samping kiri Candi Borobudur yang terlihat tidak utuh, hanya sebagian stupa besar yang terlihat, sisanya stupa stupa kecil terlihat rapih tersusun, dengan nuansa langit biru cerah berpadu dengan awan putih. 
Di bagian atas kiri poster terdapat Logo Gram berwarna warni disanding Logotype Asian Games 2018 Jakarta Palembang berwarna putih menggunakan penggabungan huruf kapital dan standar. Pada bagian ujung kanan atas juga terdapat tulisan dalam bentuk angka 18-8-18 dengan bentuk tebal berwarna putih dan dibagian bawah angka tersebut terdapat tulisan energi of Asia dengan huruf kapital berwarna putih. Di tengah poster dan di atas gambar model terdapat tulisan "Sambut Energi Asia" menggunakan huruf kapital berwarna putih yang dengan shadow hitam, yang merupakan headline dari poster tersebut. Di bagian bawah tengah poster terdapat tulisan alamat website, logo media sosial facebook, twitter, instagram, youtube asian games 2018 berwarna putih. Bagian kanan bawah poster terdapat ikon wilayah dengan tulisan Borobudur Magelang Jawa Tengah berwarna putih menggunakan huruf kapital.

\section{Analisis Formal}

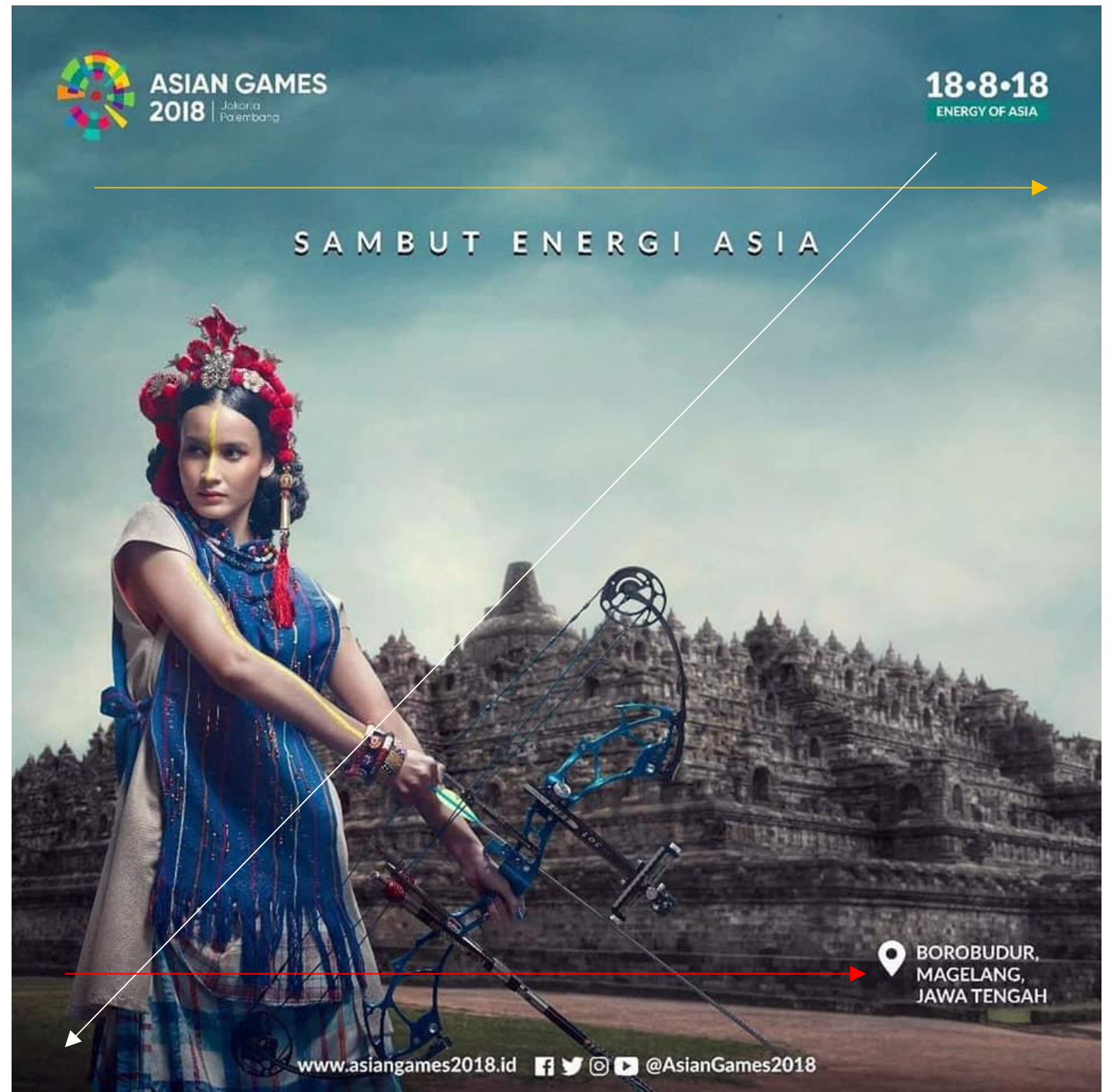

Gambar 3 Poster Asian Games (dok. Daring BrilioNet, 2019)

Tahap kedua Membahas, bagaimana elemen-elemen dasar dalam suatu karya desain terjalin menjadi sebuah susunan layout (secara teknis); warna, layout, komposisi, jenis huruf dll. Pada poster ini sangat teroganisir dimulai dari penempatan elemen-elemen poster (headline, logo, sub headline, visual utama, background sampai bodytext) yang terstruktur, besar kecil 
huruf, sehingga penikmat atau pembaca iklan bisa mengetahui pesan atau inforasi dari poster tersebut. Posisi elemen poster yang menciptakan jalur visual yang tercipta juga memudahkan kita menangkap mana informasi yang pertama harus

Warna-warna yang tersusun dalam poster ini seperti warna biru pada bagian baju yang dikenakan model, gagang utama busur panah, putih pada tulisan, abu/krem pada bagian dalam baju yang dikenakan model, abu-abu tua dan hitam pada bagian Candi Borobudur, Hitam terlihat pada aksen busur panah, biru langit gradasi putih dengan sedikit nuansa hijau terlihat pada bagian atas poster atau gambar langit-langit dan list pada tulisan energy of asia, coklat pada bagian jalan di bawah Candi dan hijau tua pada bagian rumput. Garis jelas terlihat pada bagian logo type pemisah tulisan Enery Of Asia dengan Jakarta Palembang dan kesan garis terlihat presisi membentuk sudut titik hilang dari kiri ke kanan membentang secara diagonal terlihat dari bentuk Candi, kemudian terlihat diagonal presisi dari kiri atas ke bagian bawah terlihat dari bentuk busur panah.

Bidang yang nampak pada poster ini terlihat rapi tersusun, mulai dari ukuran logo di bagian atas kiri poster, menuju angka 18-8-18 di bagian atas kanan poster terlihat cukup luas, kemudian bidang menuju headline poster di tengah juga seimbang dengan besar huruf. Apabila membandingkan bidang yang tersusun antara visual seorang model dengan visual background Candi Borobudur, jelas kita dapat menentukan mana-mana yang menjadi visual utama dan mana yang menjadi visual pendukung. Bidang terakhir dapat terlihat ketika icon lokasi dan keterangan media sosial kegiatan tertulis di bagian bawah poster.

Komposisi dari poster tersebut terlihat seimbang, tapi lebih ke arah asimetris balance (keseimbangan yang tidak proporsional antara kiri dan kanan), akan tetapi tetap teratur, terlihat dari objek utama dalam bentuk model yang memegang busur panah dengan tambahan tulisan dan logo terlihat diimbangi oleh bentuk bagian Candi Borobudur yang condong ke kiri, akan tetapi dengan bagian kanan lebih menonjol, juga adanya penambahan tulisan angka dan icon tempat serta keterangan lokasi. Penekanan dalam poster berupa pemanfaatan elemenelemennya dapat menentukan arah pembaca sesuai kebutuhannya, dalam poster ini penekanan sekaligus pusat perhatian terlihat pada sosok model yang menggunakan pakaian khas nusantara sambil membawa busur panah (mewakili cabang olahraga yang dipertandingkan) jelas membantu pembaca memahami informasi yang ingin disampaikan oleh si perancang.

\section{Interpretasi Narasi Visual}

Pada tahap ketiga adalah menafsirkan makna suatu karya, mengupas teknik atau cara yang digunakan untuk mengungkapkan keinginan desainer dalam karya desain yang sedang kita diamati.

\section{Memori:}

Ada 4 elemen yang mengingatkan memori visual seseorang dalam poster ini.

1. Sarung

Di Asia Tenggara, sarung merupakan pakaian yang hampir merata ada di setiap Negara. Sebagaimana di berbagai bangsa di dunia, sarung di Asia Tenggara juga di kenal dengan banyak nama, model dan design. Di Myanmar, sarung dinamakan longyi; Di Kamboja, busana ini dikenal dengan nama sampot; di Laos dan tempat sebagian wilyah Thailand disebut Sinh (Lao: వั้บ, Thai: ซิ่น). Sedang di Thailand sendiri, busana ini disebut $p a$ $k a o$ mah (Thai: ผ้าขาวม้า) untuk laki-laki dan pa toong (Thai: ผ้าถุง) untuk wanita.

Di daerah Melayu hingga ke Timur gugusan pulau di Nusantara, seperti Malaysia, Sumatera, Jawa, Bali, Kalimantan, Sulewasi hingga ke Filipina, busana ini memiliki nama yang identik satu sama lain, mulai dari sarung yang secara umum dikenal di Indonesia dan 
Malaysia, hingga sebutan-sebutan lain yang menunjukkan perbedaan model dan motifnya, seperti kain (Malaysia, dan sebagian besar daerah di Indonesia), songket (Minangkabau dan Palembang), batik (jawa), samping (melayu hingga pulau Jawa), sabok (di Sarawak), kebaya (di Jawa dan Bali), malong (di Mindanao); serta untuk wanitanya, orang-orang Filipina menyebut busana ini dengan saya atau tapis, nama yang sama juga dapat kita temukan di daerah Lampung, dimana Tapis adalah kain tradisonal suku Lampung.

Di Indonesia, istilah sarung biasanya menunjukkan ke jenis kain yang berbentuk tabung dan dijahit menyatu di kedua sisinya. Model jenis ini adalah yang umum seperti digunakan oleh suku Badui yang tinggal di Yaman. Sarung Yaman berasal dari kain putih yang dicelupkan ke dalam neel yaitu pewarna hitam. Sarung Yaman terdiri dari beberapa variasi, termasuk model Assafi, al-kada, dan annaqshah. Adapun sarung dalam arti luas yang sudah tersentuh oleh "kejenuisan nusantara", bisa dibedakan secara umum dari metode pembuatannya. Beberapa diantara adalah tenun ikat, Songket, serta Tapis. Kain ikat dapat dibedakan dari kain songket berdasarkan jenis benang. Songket umumnya memakai benang emas atau perak. Motif kain songket hanya terlihat pada salah satu sisi kain, sedangkan motif kain ikat terlihat pada kedua sisi kain (Ganalslamika).

2. Candi Borobudur

Candi Borobudur merupakan salah satu dari tujuh keajaiban di Dunia, andi Borobudur merupakan salah satu Candi terbesar di Indonesia. Candi borobudur merupakan salah satu Candi Buddha yang terletak di Magelang, provinsi Jawa Tengah. Candi Borobudur terletak kurang lebih $40 \mathrm{~km}$ di sebelah barat laut kota jogja. Dengan kendaraan umum, mobil dan sepeda motor hanya memakan waktu sekitar 1 jam perjalanan dari kota Jogja.

Candi Borobudur di bangun pada masa penganut ajaran Buddha Mahayana tepatnya sekitar tahun 750-800 an Masehi. Candi Borobudur pun masuk dalam 7 keajaiban dunia, selain karena menjadi yang terbesar, Candi Borobudur menjadi Candi Buddha yang tertua karena di bangun jauh sebelum Candi Angkor Wat di Kamboja yang masih baru dibangun kira-kira pada pertengahan abad ke-12 oleh Raja Suryavarman II (borobudurpark.com; Saddoen).

Nama Candi Borobudur sendiri berasal dari katabara dan budur. Dalam istilahnya, bara memiliki arti kompleks biara dan kata budur yang mempunyai arti atas. Yang kemudian, jika digabungkan menjadi kata barabudur dibaca borobudur yang berarti kompleks biara di atas. Sesuai dengan namanya juga, Candi Borobudur terletak tepat di atas sebuah bukit sebagai komplek biara yang sungguh megahnya (Saddoen).

Candi Borobudur awal mulanya adalah berupa rancangan bangunan berupa stupa tunggal yang sangat besar yang memahkotai puncaknya. Namun karena pertimbangan bahwa stupa akan terlalu besar dan berat yang beresiko membahayakan jika diletakkan di puncak, maka kemudian stupa tersebut dibongkar dan digantikan dengan tiga barisan stupa dengan ukuran kecil dan satu stupa induk seperti sekarang ini.

Megahnya bangunan Candi Borobudur sendiri terbagi ke dalam 10 tingkat yang berbentuk punden berundak. Filosofi yang terkandung pada 10 tingkat bangunan Candi Borobudur tersebut adalah untuk melambangkan tahap dan proses hidup manusia.

Bangunan Candi Borobudur memiliki enam teras berbentuk bujur sangkar yang di atasnya mempunyai atau terdapat pelataran melingkar. Pada dinding Candi juga dihiasi dengan kira-kira 2.672 panel relief serta terdapat 504 arca Buddha. Stupa utama Borobudur yang paling besar terletak di tengah sekaligus menjadi mahkota di puncak bangunan ini. Stupa puncak tersebut pun dikelilingi oleh tiga barisan dari 72 stupa berlubang yang 
terdapat arca Buddha yang duduk bersila di tengah-tengah bunga teratai sempurna dengan mudra (sikap tangan) dharmachakra mudra (memutar roda dharma).

3. Panahan

Konon panahan sudah ada sejak 25.000 tahun lalu, Manusia purba pada saat itu membuat busur panah dari ranting pohon yang berbentuk melengkung. Mereka juga membuat anak panahnya dari ranting yang lebih kecil. Pada zaman logam, orang-orang tidak membuat panah dari ranting, tapi dari logam. Panah logam ini lebih berbahaya karena lebih keras dan tidak mudah patah. Sejak saat itu juga, panah hanya digunakan sebagai alat berburu, tapi juga sebagai alat perang.

Di masa modern ini, panahan tidak lagi digunakan sebagai alat berburu dan senjata perang. Panahan sudah dialihfungsikan menjadi sebuah kegiatan olahraga yang pastinya menyehatkan tubuh. Pada tahun 1600 -an, olahraga panahan ini sangat populer di Inggris. Turnamen memanah pertama kali diselenggarakan di Yorkshire, Inggris, pada 1673. Pada 1760, dibentuklah organisasi panahan di Inggris dan sejak itulah diselenggarakan turnamen panahan setiap tahunnya. Namun begitu, Federasi Panahan Internasional baru dibentuk pada 1931.

\section{Attention:}

Menurut Barnard, etimologi kata fashion terkait dengan bahasa Latin, factio artinya "membuat". Karena itu, arti asli fesyen adalah sesuatu kegiatan yang dilakukan seseorang. Sekarang, terjadi penyempitan makna dari fesyen. Fesyen sebagai sesuatu yang dikenakan seseorang, khususnya pakaian beserta aksesorinya.

Perkembangan tren fesyen yang semakin pesat membuat beberapa pakaian tradisional disulap menjadi lebih modern. Salah satunya ialah kain tenun dari beberapa daerah di Indonesia. Peningkatan upaya pelestarian kain tenun kini juga tengah digalakkan oleh pemeritah setempat agar kain ini terus menjadi warisan banga yang patut untuk dijaga. Kain tenun yang didesain lebih modern kini di desain agar lebih wearable agar dapat digunakan oleh para milenial.

Gaya Fesyen yang diusung pada poster Asian Games 2018 adalah Happa. Happa, yang berarti 'setengah' atau 'budaya campuran', adalah pendekatan Mel dan Andien dalam menggabungkan apa yang saat ini ada dalam mode Asia dan juga tren global saat ini. Timur bertemu Barat, duo dinamis ingin menunjukkan kepada dunia bahwa mode tidak selalu harus glamor - itu bisa menyenangkan, kontemporer, dan aneh pada saat yang sama. Dari palet warna yang luas hingga ilustrasi kreatif, Happa pada dasarnya adalah perpaduan antara seni kelas satu Mel dan pengetahuan ensiklopedis Andien tentang mode. Pesannya adalah, bahwa para pemakainya (model dalam iklan salah satunya) tidak terlihat glamour tetapi tetap seru khas milenial.

Saat ini Candi Borobudur menjadi salah satu destinasi wisata yang paling sering dikunjungi oleh para wisatawan, baik wisatawan dalam negeri maupun manca negara. Megahnya arsitektur Candi Borobudur, luas area, dan juga sejarahnya membuat candi ini masuk menjadi salah satu warisan budaya dunia, dan termasuk kedalam tujuh keajaiban dunia. Bahkan sudah ditetapkan langsung oleh UNESCO.

Wisata ke Candi Borobudur bisa bermanfaat banyak buat kita. Selain liburan, sekaligus juga belajar sejarah dan mengagumi hebatnya budaya serta kemampuan leluhur kita dulu. Kekayaan budaya dan sejarah candi ini sudah di akui dunia, ada baiknya kita dapat mengetahuinya bahkan mencintainya juga. 
Saat ini olahraga panahan menjadi salah satu olahraga favorit masyarakat di dunia, khususnya di Indonesia, buktinya panahan selalu menjadi cabor yang dilombakan di setiap event olahraga tingkat daerah, nasional, bahkan dunia, dan kabar baiknya adalah, beberapa kali, olah ragawan cabang panahan kita Indoneisa, berhasil menyabet beberapa medali.

Expectation:

Poster asian games 2018 ini memiliki beberapa seri, salah satunya adalah seri model menggunakan gaya fesyen Happa, hasil kolaborasi penyanyi Andien dengan desainer Mel Ahyar, memegang busur panah dengan gagahnya, berdiri dengan latar belakang Candi Borobudur, poster ini tidak hanya berfungsi sebagai media promosi kegiaan Asian Games 2018, juga sebagai media promosi wisata Indonesia di kancah Asia, bahkan dunia.

Dengan poster ini pula, kita, Bangsa Indonesia dapat berbicara secara langsung di Kancah Asia, bahkan dunia, menyatakan bahwa kekayaan budaya kita sangat hebat, besar bahkan luar biasa. Tidak hanya kekayaan budaya, bahkan prestasi anak bangsa dalam bidang olah raga, fesyen pun terlihat.

\section{SIMPULAN}

Desain poster Asian Games 2018 yang elegan dan to the point ini diaplikasikan menggunakan penggabungan dua buah konsep, yaitu konsep tradisi dan modern, dengan penekanan pada area fesyen Happa, olahraga panahan dan destinasi wisata sejarah Bangsa Indoneisa 'Candi Borobudur'. Pesan yang ingin disampaikan pada poster ini adalah, bahwa kita bangsa Asia pada umumya dan Bangsa Indonesia pada khususnya merasa bangga dengan kekayaan budaya yang dimiliki, baik itu dalam hal fesyen, artefak bangunan bersejarah bahkan hingga ke olah raga, dan sudah seharusnya, kita putra dan putri Bangsa Indonesia harus terus melestarikan juga menjunjung tinggi nilai-nilai tersebut. Poster ini menampilkan seorang model menggunakan gaya fesyen Happa, mempresentasikan sarung dan kain tenun, di mana di sejumlah negara di Asia juga mengenal bahan tersebut, tidak terlihat glamour, akan tetapi tepat terlihat kekinian, elegan dan berkarakter, memagang busur panah sebagai salah satu perwakilan cabang olah raga yang dilombakan di Asian Games 2018, sangat berhubungan dengan kekayaan budaya dan sejarah bangsa kita sebagai penyelenggaran, dia berdiri mantap di depan Candi Borobudur, sebagai salah satu destinasi kebanggan Bangsa Indonesia, juga bagian dari tujuh keajaiban dunia.

Intinya adalah, Karakter Bangsa Indonesia terlihat jelas dalam poster ini, baik dari sisi personal/model, karakter wajah, atribut yang digunakan, hingga latar belakang yang ditampilkan, oleh karenanya kita sebagai bangsa Asia pada umumnya dan Bangsa Indonnesia pada khususnya wajib merasa bangga akan kekayaan budaya dan sejarah yang kita miliki, dan itu juga menunjukkan, bahwa kita Bangsa Indonesia adalah Bansa yang Besar.

\section{UCAPAN TERIMA KASIH}

Dengan hormat, Sehubungan dengan sudah selesainya penulisan naskah ini, kami segenap tim peneliti mengucapkan terima kasih yang sebesar-besarnya atas bantuan Bapak/lbu, saudara/i yang telah bersedia menjadi mitra, yang telah sudi menyampaikan sumbangan ide, gagasan dan pemikiran dalam melakukan pembenahan dan penyempurnaan naskah ini. Terima kasih dan penghargaan setinggi-tingginya kami sampaikan kepada:

1. Program Studi DKV FISS UNPAS Bandung 
2. Prof. Yasraf Amir Piliang sebagai Dosen Budaya Visual di Program Doktoral ITB

3. Dr. Irma Damayanti sebagai Dosen Budaya Visual di Program Doktoral ITB

4. Dr. Wawan Setiawan dari Universitas Pasundan

5. Tata Kartasudjana, M.Ds. dari Universitas Pasundan

\section{DAFTAR PUSTAKA}

Barnard, Malcom. Fashion as Communication. First edition, Routledge, 1996.

borobudurpark.com. "Borobudur: Inspiring Heritage." PT. Taman Wisata Candi http://borobudurpark.com/temple/borobudur/. Accessed 16 Desember 2019.

Ganalslamika. "Sarung (2): Model, Motif Dan Makna Filosofisnya." Gana Islamika 14 Januari 2018 https://ganaislamika.com/sarung-2-model-motif-dan-makna-filosofisnya/. Accessed 17 Desember 2019.

Piliang, Yasraf Amir. "Narasi Visual." Materi Perkuliahan, Institut Teknologi Bandung, 2019. Program Doktoral.

Saddoen, Arifin. "Sejarah Candi Borobudur, Asal Usul, Pendiri, Gambar Dan Penjelasannya." TheMoonDogies https://moondoggiesmusic.com/sejarah-candi-borobudur/. Accessed 17 Desember 2019.

Shimp, Terence A. Periklanan Promosi. translated by Revyani Sjahrial and Dyah Anikasari, ke-5 edition, Erlangga, 2000. Jilid 1. 